\title{
IN VITRO SENSITIVITY OF BOTRYTIS CINEREA TO RESINOUS EXUDATES OF HELIOTROPIUM FILIFOLIUM AND GERANYL DERIVATIVES COMPOUNDS
}

\author{
LEONORA MENDOZA*1, BRENDA MODAK, RENÉ TORRES AND MILENA COTORAS
}

Facultad de Quimica y Biología, Universidad de Santiago de Chile, Casilla 40-Correo 33, Santiago-Chile

(Received: 3 October 2007 - Accepted: 3 January 2008)

\begin{abstract}
The activity of the extract of Heliotropium filifolium, of the natural compounds obtained from its resinous exudates, filifolinol and filifolinyl senecionate, and of the synthetic derivative of filifolinol, filifolinoic acid, on the mycelial growth of the phytopathogenic fungus Botrytis cinerea was analyzed in liquid and solid media. The extract of H. filifolium, filifolinol, and filifolinoic acid reduced mycelial growth of this fungus. The effect of these compounds was dose-dependant. The compound filifolinyl senecionate was inactive in all the tested conditions. The extract of $H$. filifolium and filifolinol retarded the germination of conidia of the fungus.
\end{abstract}

Keywords: Botrytis cinerea; Heliotropium filifolium; geranyl derivatives; antifungal activity

\section{INTRODUCTION}

Botrytis cinerea, the agent of the gray mould, is a facultative phytopathogenic fungus that attacks flowers, fruits, leaves and stems of more than two hundred plant species ${ }^{1}$. Diseases caused by this fungus produce considerable losses to crops in the field and during storage ${ }^{2,3} . B$. cinerea has traditionally been controlled by commercial fungicides (dicarboximides and benzimidazoles). However, the use of these fungicides has caused serious problems such as the appearance of highly resistant strains and the contamination of soil and water 4 .

Some naturally occurring substances found in higher plants as terpenoids (sesquiterpenoids, diterpenoids, triterpenoids, saponins, etc.), aromatic compounds (flavonoids, stilbenes, quinones, etc), nitrogen-containing compounds (alkaloids, amines, amides) and aliphatic compounds (long chain alkanes, fatty acid, etc) show antifungal properties ${ }^{5-11}$.

Little information is available in the literature on antifungal activity of natural products against $B$. cinerea. Some flavonoids, ${ }^{12}$ diterpenoids, ${ }^{13}, 14$ sequiterpenoids, ${ }^{15}$ monoterpenoids, ${ }^{16}$ stilbenes, ${ }^{17,18}$ steroidal glycoalkaloid ${ }^{19-21}$ and triterpenoids ${ }^{22}$ have effect against this fungus (inhibition mycelia growth, cytological changes, toxic action and protection cucumber tissue, etc).

Heliotropium filifolium (Fam. Heliotropiaceae) is a resinous bush that grows in desert environments ${ }^{23}$. A resinous exudate covers its foliar surface and the stem. The secondary metabolites that compose the resin consist of a mixture of flavonoids and geranyl aromatic derivatives, such as filifolinol $\mathbf{1}^{24}$, the first example of a spiro benzodihydrofuranyl terpene and the esther derivative filifolinyl senecionate $2{ }^{25}$.

The aim of the present study was to evaluate the fungitoxic effect against $B$. cinerea of the extract obtained from H. filifolium and of the genaryl derivative compounds, filifolinol and filifolinyl senecionate, purified from resinous exudates of $H$ filifolium. Due to the special structure of these compounds and the influence of the functional groups in the biological activity, the effect of a compound obtained by hydrolysis of compound $\mathbf{1}$ called filifolinoic acid $\mathbf{3}^{26}$ on $B$. cinerea was also analyzed.

\section{EXPERIMENTAL}

Fungal isolate and culture conditions

In this study the isolate G29 of $B$. cinerea was used. This isolate was originally isolate from a naturally infected grape (Vitis vinifera). This isolated has been genetically characterized ${ }^{27}$ and it is considered resistant to fungicide dicarboximide ${ }^{28}$. It was maintained on malt-yeast extract agar slants $(2 \%$ malt extract, $0.2 \%$ yeast extract and $1.5 \%$ agar) at $4^{\circ} \mathrm{C}$. The fungus was grown in the following culture media:

a) Solid media: Two solid media were used: malt-yeast extract agar medium and soft agar medium ( $2 \%$ malt extract, $0.2 \%$ yeast extract and $0.6 \%$ agar).

b) Liquid media. The fungus was cultured in malt-yeast extract medium ( $2 \%$ malt extract, $0.2 \%$ yeast extract). It was also grown in liquid minimum medium which contained: $\mathrm{KH}_{2} \mathrm{PO}_{4}(1 \mathrm{~g}), \mathrm{K}_{2} \mathrm{HPO}_{4}(0.5 \mathrm{~g}), \mathrm{MgSO}_{4} \cdot 7 \mathrm{H}_{2} \mathrm{O}(0.5$ $\mathrm{g}), \mathrm{KCl}(0.5 \mathrm{~g}), \mathrm{FeSO}_{4} \cdot 7 \mathrm{H}_{2} \mathrm{O}(0.01 \mathrm{~g})$ per liter. Ammoniun tartrate $(25 \mathrm{mM})$ was used as nitrogen source and $1 \%(\mathrm{w} / \mathrm{v})$ glucose was added as carbon source.

Isolation of from filifolinol and filifolinyl senecionate from $H$. filifolium

The compounds $\mathbf{1}$ and $\mathbf{2}$ used in this study are shown in the Figure 1. These compounds were purified from the resinous exudate of $H$. filifolium (Miers) Reiche (ST-2214 SSUC) as has been described ${ }^{24,25}$. The hemisynthetic compound, filifolinoic acid 3 (Figure 1) was obtained by hydrolysis from compound $\mathbf{1}^{24-26}$.

$\underbrace{2}_{0}$

$1 \quad R=H$<smiles>[R]C=CC(=C)C</smiles>

Figure 1. Structure of compounds 1-3

Fungitoxicity assay against $B$. cinerea

a) Effect on mycelial growth

Fungitoxicity of H. filifolium extract and of the purified compounds was assessed using the radial growth test on malt-yeast extract agar ${ }^{14}$. The extract or the compounds were dissolved in methanol to different final concentrations. Cultures were incubated in the dark at $22^{\circ} \mathrm{C}$ for nine days. Mycelial growth diameters were measured daily. The mean value of at least three different experiments was used for calculation. Each experiment was done in triplicate. The results were expressed as percentage of inhibition of mycelial growth on the control, after 72 hours of incubation.

Fungitoxicity of $H$. filifolium extract or genaryl derivatives was also assessed in liquid media ${ }^{28}$. Flasks were inoculated with conidia to a final concentration of $3 \times 10^{5}$ conidia $/ \mathrm{mL}$. Cultures were incubated in the static condition at $22{ }^{\circ} \mathrm{C}$. After 5 days of incubation the wet weight of the mycelia was determined.

b) Effect on germination of B. cinerea conidia.

Conidial germination assays were carried out on microscope slides coated with soft agar medium ( $2 \mathrm{~mm}$ thickness). Extract or compounds were added dissolved in methanol at a final concentration of 40 or $160 \mu \mathrm{g} / \mathrm{mL}$. In the control only methanol was added, the final methanol concentration was identical in control and treatment assays ${ }^{28}$. The percentage of germination was estimated by counting the number of germinated conidia in five microscope fields each containing 40 conidia. Conidia were judged to have germinated when the germ tube length was equal to or greater than conidial diameter. Each experiment was done at least in triplicate. 


\section{RESULT AND DISCUSSION}

To evaluate antifungal activity of $H$. filifolium extract and the purified compounds, the effect on mycelial growth in solid and liquid media was determined.

In solid medium, the extract and the compounds, at $0.04 \mathrm{mg} / \mathrm{mL}$, did not inhibit the mycelial growth (data no shown). At higher concentrations, the extract and compounds $\mathbf{1}$ and $\mathbf{3}$ were active (Figure 2); however, the effect fluctuated at different concentrations. At $0.08 \mathrm{mg} / \mathrm{mL}$ compound $\mathbf{3}$ was more active than the others, while at $0.64 \mathrm{mg} / \mathrm{mL}$ compound 1 presented the highest inhibitory effect, around $60 \%$. Compound 2 was inactive at all concentrations tested (data no shown). The fungicide iprodione at $0.04 \mathrm{mg} / \mathrm{mL}$ (positive control) produced a $57.3 \%$ of inhibition, data no shown. The mycelium growth rate during the exponential phase was $1.58 \mathrm{~cm} /$ day for the control and it decreased to 1.44 and $1.26 \mathrm{~cm} /$ day in the presence of compound 1 at 0.08 $\mathrm{mg} / \mathrm{mL}$ and $0.64 \mathrm{mg} / \mathrm{mL}$, respectively. These results show that the growth rate decreased at higher concentrations of the compound $\mathbf{1}$. In the extracts and in the compound 3 the results are the same.

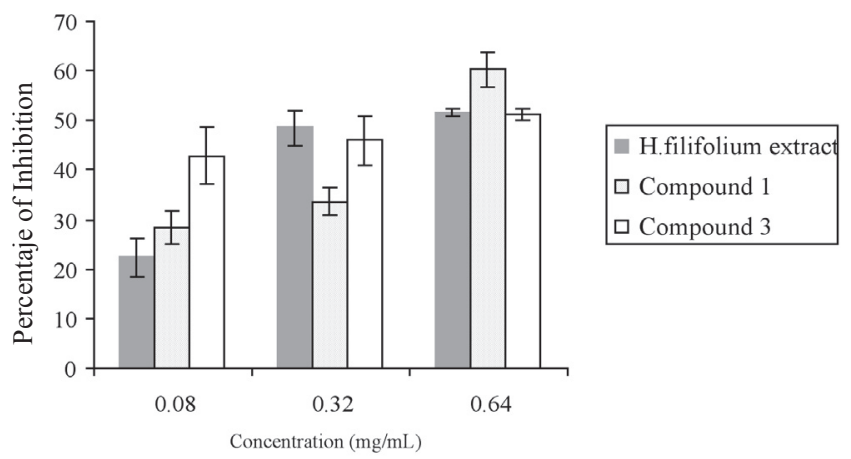

Figure 2. Effect of different concentrations of H.filifolium extract and compounds filifolinol and filifolinoic acid on the mycelial growth of $B$. cinerea. Compounds dissolved in methanol were added to $5 \mathrm{~mL}$ of soft agar medium at different concentrations. Controls contained methanol at the same concentrations as treatment assays. Each point represents the average of at least three independent experiments \pm standard deviation.

The effect of the extract and the compounds was also determined in liquid media (Figure 3). In malt-yeast extract culture medium, the extract and compounds at $40 \mu \mathrm{g} / \mathrm{mL}$ inhibited mycelium growth in approximately $42 \%$. The same results were obtained in the minimum medium (result not shown). The antifungal activity of the extract and compounds was not different in both liquid medium probably because the solubility is similar and the interaction fungus-compounds are similar too.

At $40 \mu \mathrm{g} / \mathrm{mL}$, the antifungal effect is higher in liquid medium than in solid medium. Probably, in liquid medium, a higher interaction among the compounds and the fungus would occur.

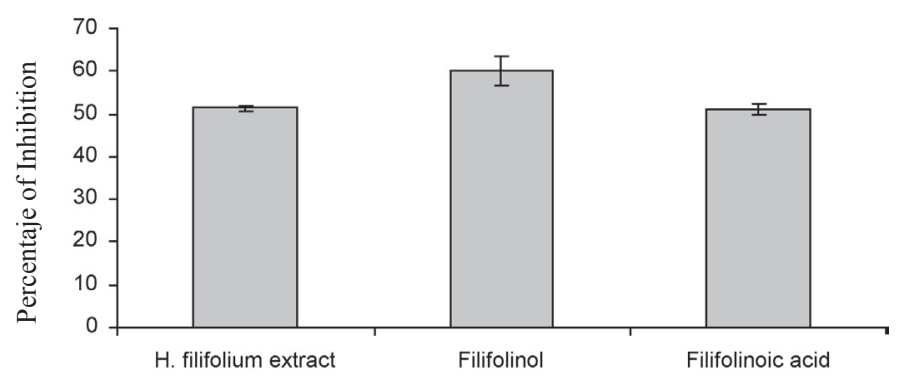

Figure 3. Effect of $H$. filifolium extract and compounds filifolinol and filifolinoic acid on the mycelial growth of $B$. cinerea in malt yeast extract liquid medium. Compounds dissolved in methanol were added at a final concentration of $40 \mu \mathrm{g} / \mathrm{mL}$. Controls contained methanol at the same concentrations as treatments. Percentages of inhibition relative to the control with methanol were calculated after five days of incubation. Each bar represents the mean of at least five independent experiments \pm standard deviation.
Finally, the effect of extract, compound $\mathbf{1}$ and compound $\mathbf{3}$ on germination conidia was analyzed. The extract and the compound $\mathbf{1}$ did not effect the germination of $B$. cinerea conidia at $40 \mu \mathrm{g} / \mathrm{mL}$, but at $160 \mu \mathrm{g} / \mathrm{mL} \mathrm{H}$. filifolium extract and compound $\mathbf{1}$ did retard the germination. (Figures 4A and B). These results suggest that the concentration is important for the fungitoxic effect. The compound $\mathbf{2}$ and $\mathbf{3}$ were inactive (results not shown). A similar effect has been observed with the fungicide fenhexamid that inhibits the germination of $B$. cinerea conidia only at relatively high concentrations. This fungicide is also a strong inhibitor of mycelium growth of this fungus ${ }^{29}$ but its mechanism of action on $B$. cinerea has not been elucidated.
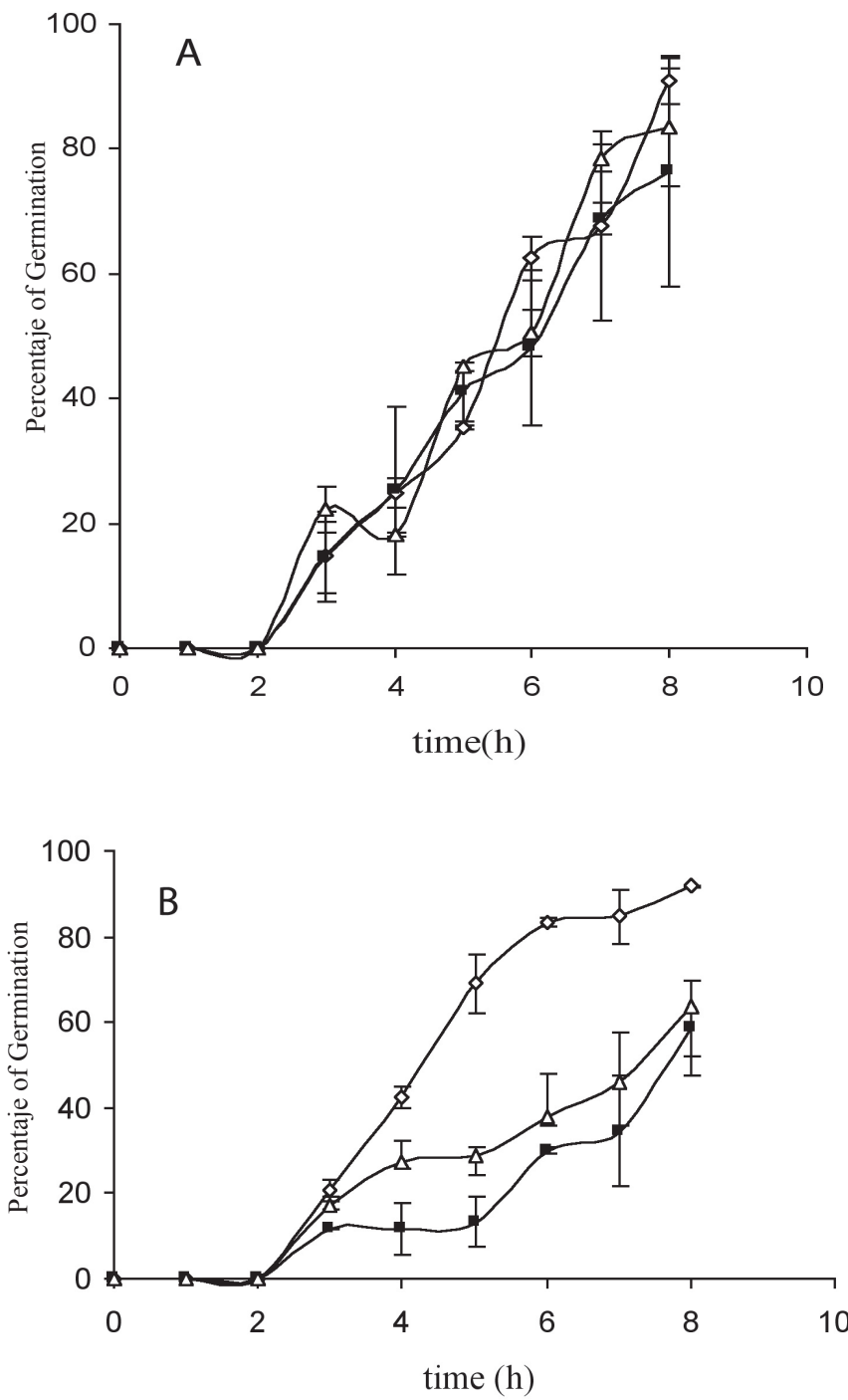

Figure 4. Effect of $H$. filifolium extract and filifolinol on conidia germination of $B$ cinerea.

The $H$. filifolium extract $(\mathbf{\square})$ and filifolinol $(\Delta)$ were dissolved in methanol and added to final concentrations of $40 \mu \mathrm{g} / \mathrm{mL}$ (A) or $160 \mu \mathrm{g} / \mathrm{mL}$ (B). Controls contained methanol at the same concentrations as treatment assays $(\diamond)$.

There are not data in literature of the effect of these compounds against $B$. cinerea. It has been reported that filifolinol had an inhibitory effect against Fusarium moniliforme and Aspergillus niger (61\% and 36\% mycelial growth inhibition at $0.5 \mathrm{mg} / \mathrm{mL}$, respectively $)^{30}$.

Also, it has been reported that the resinous exudate of $H$. filifolium and some compounds isolated form them (filifolinol, filifolinyl senecionate and filifolinone), presented antiviral activity against of human virus Polio stump sabin, Herpes simplex $1, H$. simplex 2, Junin and Respiratory syncitial virus ${ }^{31}$. 
Aditionally $H$. filifolium extract, filifolinoic acid, filifolinol and filifolinyl senecionate were assay against Hantavirus. The results showed that resin and their main component filifolinol inhibited the viral development at $10 \mu \mathrm{g} / \mathrm{mL}$ in $36 \%$ and $27 \%$ respectively. The other compounds did not show effect ${ }^{25}$.

The results of the present work, together with the antiviral activity results ${ }^{26,31}$ show that compound $\mathbf{1}$ is the most active compound of the extract and that the biological activity of the extract could be explained by its presence. These results suggest that the hydroxyl group at C-7' position is important for the fungitoxic effect because, when this group is free the compound presents activity (1 and $\mathbf{3}$ ), and if it is esterificated the compound is inactive (compound 2). Possibly, the hydroxyl group would increase the polarity of compounds $\mathbf{1}$ and $\mathbf{3}$ and this characteristic might be important for the antifungal activity. This same situation has been described for the diterpenoids kaurenoic acid and $3 \beta$-hydroxy-kaurenoic acid ${ }^{14}$. The later presented higher antifungal activity than the non-hydroxylated compound. This suggests that the hydroxyl group would increase the polarity of the compound, thus favoring its interaction with the fungus.

On the other hand, the mycelium growth and the germination of $B$. cinerea are not completely inhibited by these compounds, but just retarded by them. These results could be explained by the ability of $B$. cinerea to biotrasform the geranyl derivative to a less active metabolite. In fact, it has been reported that B. cinerea biotrasforms several compounds ${ }^{32}$. Another possible explanation could be that filifolinol and its acid derivative induce the expression the ATPbinding cassette $(\mathrm{ABC})$ transporters in $B$. cinerea to eliminate toxic compounds. It has been reported that some compounds as antibiotics, resveratrol and the fungicide fenpiclonil induced expression of several $\mathrm{ABC}$ transporter genes in B. cinerea $^{33-34}$.

\section{REFERENCES}

1. Y. Elad, K. Evenses, Phytopathol., 85, 637, (1995).

2. W. R. Jarvis, In The Biology of Botrytis. Epidemiology, J. R. Coley-Smith, K. Verhoeff, W. R. Jarvis, eds. Academic Press, London, 1980; pp 219250.

3. P. Leroux, Pestic. Sci., 47, 191, (1996).

4. B. Latorre, V. Flores, A. M Sara, A. Roco, Plant Dis. 7, 990, (1994).

5. M Weidenbörner, H. Hindorf, H. Chandra Jha, P. Tsotsonos, H. Egge, Phytochemistry, 29, 801, (1990).

6. M. Weidenbörner, H. Hindorf, H. Chandra Jha, P. Tsotsonos, H. Egge, Phytochemistry, 29, 1103, (1990).

7. S. Phongpaichit, E. Schneider, A. Picman, P. Tantiwachwuttikul, Biochem. Syst. Ecol., 23, 17, (1995).

8. R. Grayer, J. Harbone, Phytochemistry, 37, 19, (1994).

9. A. Osbourn, Plant Cell, 8, 1821, (1996).

10. J. Harborne. Biochem. Syst. Ecol. 27, 335, (1999).
11. A. Picman, E. Schneider, J. Gershenzon, Biochem. Syst. Ecol., 18, 325, (1990).

12. M. Cotoras, C. García, C. Lagos, C. Folch, L. Mendoza, Bol. Soc. Chil. Quim. K 46, 433, (2001).

13. A. Martin, J. Agric. Food Chem. 51, 7607, (2003).

14. M. Cotoras, L. Mendoza, C. Folch,. J. Agric. Food Chem. 52, 2821, (2004).

15. M. Jochen, J. B. Speakman, Phytochemistry, 65, 2583, (2004).

16. C. Bouchra,. J. Ethnopharmacol., 89, 165, (2003).

17. P. Langcake, W. McCarthy, Vitis, 18, 244, (1979).

18. M. Adrian, P. Jeandet, J. Veneau, L. Weston, R. Bessis, J. Chem. Ecol., 23, 1689, (1997).

19. T. Quidde, A. Osbourn, P. Tudzynski, Mol Plant Pathol. 52, 151, (1998).

20. K. Verhoeff, J. Liem, Phytopathol. Zeitschrift., 82, 333, (1975).

21. E. A. J. Keukens, T.de Vrije, C. van den Boom, P. de Waard, H. H. Plasman, F. Thiel, V. Chupin, W.M.F. Jongen, B. de Kruijff, B. B. Acta, 1240, 216, (1995).

22. N. Bar-Nun, A.M. Mayer, Phytochemistry, 29, 787, (1990).

23. N. Diane, H. Fôrther, H. Hilger, American Journal of Botany, 89, 287, (2002).

24. R. Torres, L. Villarroel, A. Urzúa, F. Delle Monache, G. Delle Monache, E. Gacs-Baitz, Phytochemistry, 36, 249, (1994).

25. A. Urzúa, B. Modak, Torres.R. Bol. Soc. Chil. Quim. 46, 175, (2001).

26. B. Modak, H. Galeno, R. Torres, J. Chil. Chem. Soc., 49, 143, (2004).

27. G. Muñoz, P. Hinrichsen, Y. Brygoo, Mycol. Res. 106, 594, (2002).

28. L. Mendoza, R. Araya-Maturana, W. Cardona, T. Delgado-Castro, C. García, C. Lagos, J. Agric. Food Chem. 53, 10080, (2005).

29. H.J. Rosslenbroich, D. Stuebler, Crop Protection, 19, 557, (2000).

30. L. Villarroel, R. Torres, A. Urzúa, M. Reina, R, Cabrera, A. GonzalezColoma, J. Nat. Prod. 64, 1123, (2001).

31. R. Torres, B. Modak, A. Urzúa, F. Delle Monache, E. Damonte, C. Pujol, Bol. Soc. Chil. Quim. 47, 259, (2002).

32. J. Aleu, I. González Collado, J. Mol. Catal. B: Enzym. 13, 77, (2001).

33. H. Schoonbeek, G. del Sorbo, M. A de Waard, Mol. Plant Microbe Interact. 14, 562, (2001).

34. H Schoonbeek, J. M. Raaijmakers, M. A. de Waard, Mol. Plant Microbe Interact. 15, 1165, (2002).

\section{ACKNOWLEDGEMENTS}

This research was supported by the Departamento de Investigaciones Científicas y Tecnológicas (DICYT) of the Universidad de Santiago de Chile, by the International Foundation for Science Grants $N^{\circ}$ F/3115-1 and C/ 28072 . 